\title{
Improving Erythropoiesis Stimulating Agent Hyporesponsiveness in Hemodialysis Patients: The Role of Hepcidin and Hemodiafiltration Online
}

\author{
Alberto Rosati $^{a}$ Fiammetta Ravaglia $^{a}$ Vincenzo Panichi ${ }^{b}$

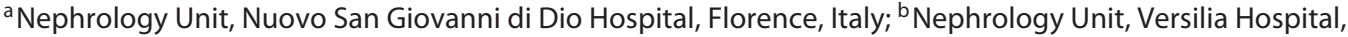 \\ Camaiore, Italy
}

\section{Keywords}

Erythropoietin stimulating agent hyporesponsiveness . Hepcidin · Erythropoietin · Anemia · Hemodiafiltration online $\cdot$ Chronic kidney disease $\cdot$ Inflammation

\begin{abstract}
Hyporesponsiveness to erythropoietin stimulating agents (ESAs) is a condition associated with increased mortality. Even after identifying the condition, the causes are difficult to treat and only partially reversible in end-stage renal disease patients. Thus, the role of more recent hemodialysis (HD) techniques in improving such conditions is an emerging issue. However, major randomized clinical trials have not confirmed the results of smaller observational studies in which online hemodiafiltration has shown some efficacy in improving patients' response to ESAs. In our interpretation, these findings are not in contrast, but they can be explained by a better understanding of the interactions between HD and ESAs on iron mobilization, first of all through the role of hepcidin. The kinetics of hepcidin removal through HD combined with the action of selected ESAs may help the clinician in prescribing the best association between HD treatment and ESAs to overcome hyporesponsiveness.
\end{abstract}

(c) 2018 S. Karger AG, Basel
(C) 2018 S. Karger AG, Basel

\section{Introduction}

Erythropoietin-stimulating agents (ESAs) are the milestone in the management of anemia associated with chronic kidney disease (CKD). Since their first use in 1989, ESAs clinical availability resulted in blood transfusion independence and iron overload avoidance in CKD and end-stage renal disease (ESRD) patients [1].

Nevertheless, the individual response to ESAs may vary greatly on the basis of various determinants, and in some cases may be poor or extremely poor, showing significant anemia despite large doses of ESAs. This condition is defined as hyporesponsiveness or resistance to ESAs and is associated with increased mortality [2-4]. Among many factors involved in ESA hyporesponsiveness, we focused on the role of hemodialysis (HD) treatment.

\section{ESA Treatment Options in HD}

In HD patients, according to 2012 Kidney Disease: Improving Global Outcomes guidelines, initiation of ESA treatment is suggested for hemoglobin level lower than 10 $\mathrm{g} / \mathrm{dL}$ with caution for CKD patients with history of stroke or an active malignancy [5], provided that other causes of 
Table 1. Current definitions used for hyporesponsiveness to erythropoietin stimulating agents

\begin{tabular}{ll}
\hline K/DOQI & 450 units/kg per week IV EPO or 300 units/kg per week subcutaneous EPO \\
\hline European guidelines & $\begin{array}{l}300 \text { units/kg per week of EPO (approximately 20,000 units/week) and } 1.5 \mu \mathrm{g} / \mathrm{kg} \\
\text { per week of darbepoetin alfa (approximately } 100 \mu \mathrm{g} / \text { week) }\end{array}$ \\
\hline KDIGO & $\begin{array}{l}\text { Initial hyporesponsiveness: no increase in hemoglobin concentration after the } \\
\text { first month of appropriate weight-based dosing }\end{array}$ \\
\hline KDIGO & $\begin{array}{l}\text { Acquired hyporesponsiveness: requiring } 2 \text { increases in ESA doses up to 50\% } \\
\text { beyond the dose at which the patient had originally been stable }\end{array}$ \\
\hline ERI & Weight-adjusted weekly ESA dose divided by the hemoglobin value \\
\hline
\end{tabular}

K/DOQI, NKF-DOQI clinical practice guidelines for anemia of chronic renal failure; EPO, erythropoietin; European guidelines; KDIGO, chapter 1: diagnosis and evaluation of anemia in CKD.

ERI, erythropoietin resistance index.

anemia are excluded and iron status has been evaluated and concomitant iron deficiency restored.

Pharmacokinetics and pharmacodynamics of recombinant erythropoietin (rHuEPO) differ on the basis of the type of ESA used and the route of administration chosen. Usually, intravenous administration is the most common among HD patients. rHuEPO isoforms have an half-life of 4-10 h, while second generations ESAs, darbepoetin alfa, and methoxy polyethylene glycol-epoetin beta have a longer half-life (24-26 and $120 \mathrm{~h}$ respectively). Thus, the definition of short-acting ESAs for $\mathrm{rHuEPO}$ isoforms and long-acting ESAs for the latter. Therefore, in HD patients, rHuEPO are administered up to 3 times per week, while darbepoetin alfa and methoxy polyethylene glycol-epoetin beta weekly to monthly. As a consequence, the bioavailability of short-acting ESAs is characterized by a high and short serum concentration peak immediately after the HD session, while long-acting ESAs ensure a more gradual decrease of serum concentration in a period of weeks.

\section{ESA Hyporesponsiveness}

As previously mentioned, an inadequate response to ESAs among CKD patients is an unfavorable prognostic factor. Hyporesponsiveness to ESAs may be present from the beginning of ESA treatment or after the treatment is established. It can be characterized by the requirement of excessive doses during initiation of therapy or by the inability to maintain target hemoglobin levels despite maximum dosage in the iron replete patient. According to different guidelines, ESA hyporesponsiveness is defined as 450 units $/ \mathrm{kg}$ per week intravenous $\mathrm{rHuEPO}$ or 300 units/kg per week subcutaneous rHuEPO (K/DOQI [6]), or 300 units/kg per week of rHuEPO (approximately 20,000 units/week), and $1.5 \mu \mathrm{g} / \mathrm{kg}$ per week of darbepoetin alfa (approximately $100 \mu$ /week; European Guidelines [7]). According to Improving Global Outcomes [5], ESA hyporesponsiveness can be distinguished in initial or acquired. Initial hyporesponsiveness appears to be a failure to increase hemoglobin concentration after the first month of appropriate weight-based dosing. Acquired hyporesponsiveness is defined as requiring 2 increases in ESA doses up to $50 \%$ beyond the dose at which the patient had originally been stable (Table 1).

Commonly, patients hyporesponsive to ESAs may also be defined as those patients who receive doses greater than those administered to $75-90 \%$ of patients in a given dialysis facility.

In order to normalize the amount of ESAs required depending on the severity of anemia, the determination of Erythropoietin Resistance Index (ERI) may be useful. Currently, ERI is defined as the weekly ESA dose per kilogram of body weight divided by hemoglobin level (gram per deciliter) [8], substituting previously proposed definitions (ESA weekly dose/Hct, ESA weekly dose/body weight/Hct). The predictive value of ERI has been proved to be higher than hemoglobin in many studies $[8,9]$. In the Italian study RISCAVID [8], conducted on 700 and $53 \mathrm{HD}$ patients in the north-western area of Tuscany, patients were divided on the basis of basal ERI into quartiles, defining patients belonging to Quartile IV as hyporesponders. In this subgroup, the predictive value of ERI both as continuous and categorical variable for fatal/nonfatal cardiovascular events appeared to be higher than the value of hemoglobin. 


\section{Causes of ESA Hyporesponsiveness}

The most common cause of resistance to ESAs is insufficient iron availability for erythropoiesis. Absolute iron deficiency may be due to external blood losses and/or exhaustion of iron stores due to an increase in erythropoiesis caused by ESA treatment. Iron-restricted erythropoiesis is a condition determined by unavailability of iron in spite of sufficient iron stores and should be considered in patients who require high doses of erythropoietin, have low transferrin saturation $(<25 \%)$, and high ferritin [10].

The malnutrition-inflammation complex syndrome or the malnutrition, inflammation, and atherosclerosis syndrome are extremely important determinants of ESA hyporesponsiveness. These conditions arise from a combination of protein-energy malnutrition and a state of chronic inflammation, which alters the metabolic processes and seriously affects the handling of iron [11]. These syndromes may be suspected by concurrent elevation in markers of inflammation and depression in nutritional markers such as albumin and cholesterol and require complex therapeutic approaches to improve. Among the causes to be assessed, periodontal disease, HIV infection, the presence of a failed kidney transplant, an occult infection of an old, nonfunctioning arteriovenous graft [10], or an increased number of vascular access-related infections are associated with higher ESA requirements.

Bone disease due to severe secondary hyperparathyroidism [12], occult malignancy, and unsuspected hematologic disorders [13], as well as hemoglobinopathies such as sickle cell disease and thalassemic trait and the aluminum accumulation in bone, currently rare, may cause ESA resistance. Some reports suggest that the administration of angiotensin-converting enzyme inhibitors and/or angiotensin II receptor antagonists may result in relative ESA resistance due to genetic determinants influencing the effect of these drugs in patients receiving ESAs [14].

\section{Role of HD in ESA Hyporesponsiveness}

HD adequacy may affect responsiveness to ESAs. This relationship was suggested by Ifudu et al. [15] in a study of 20 stable patients on maintenance HD who were being treated with $\mathrm{rHuEPO}$ and who were modestly under-dialyzed (urea reduction rate $<65 \%$ ). These patients received an increased intensity of dialysis for 6 weeks and showed a rise in hematocrit from 28.4 to $32.3 \%$ despite a constant dose of rHuEPO, while the hematocrit did not

Hepcidin and HDF Online in the Response to Erythropoiesis Stimulating Agents change in the control group. In the study conducted by Movilli et al. [16], the same results were obtained independently from the use of biocompatible membranes, confirming that adequacy of dialysis reduces the doses of recombinant erythropoietin. A change in dialysis prescription is not likely to significantly enhance the response to ESAs in patients who are already being adequately dialyzed, as the relationship between dialysis dose and hematocrit is lost at $\mathrm{Kt} / \mathrm{V}>1.33$. Use of ultrapure dialysate has been associated with reduced rHuEPO requirements, presumably related to reduction of inflammatory responses [17].

Since the availability of convective HD techniques, some pilot investigations have explored the ESA response comparing standard bicarbonate $\mathrm{HD}$, hemofiltration (HF), and on-line hemodiafiltration (OL-HDF) [18].

High convective volumes combined with high permeability membranes allow an increased clearance of middle-weight molecules, including inflammatory cytokines and peptides possibly involved in ESA resistance.

\section{Role of Hepcidin in ESA Hyporesponsiveness}

In the last decade, the hepatic hormone hepcidin (HEP) has been progressively recognized as the master regulator of the erythroid response to the inflammatory stimulus [19]. Hepcidin was first identified by Ganz and collaborators in 1998 [20]. They purified a new defensinlike peptide containing 25 amino acids and 4 disulfide bonds and named it hepcidin because its mRNA was highly expressed in the liver and because the peptide showed weak microbicidal activity in vitro. It is encoded by the HAMP gene, which produces an 84 -amino-acid preprohormone, cleaved to 60 -amino-acid prohepcidin, then the mature HEP-25 [21]. Its link to inflammation and innate immunity was noticed from the beginning, as hepcidin concentration was increased more than 100 fold in the urine of a septic donor [20]. The first correlation between iron and hepcidin was described by Pigeon et al. [22], who identified hepcidin mRNA as an ironinduced transcript. Afterwards, ferroportin was identified and demonstrated to be the receptor for hepcidin. Ferroportin is a transmembrane iron channel present in enterocytes, macrophages, and hepatocytes. The binding of hepcidin to ferroportin directly induces the endocytosis of ferroportin and its proteolysis in lysosomes [23]. Thereby, iron transport is hindered, and increased hepcidin levels can cause true iron deficiency by blocking iron release from iron stores. Conversely, low levels of 
hepcidin improve iron mobilization from stores, thus raising iron availability to match demand. Hepcidin is upregulated by both increased iron stores and inflammation, while it is downregulated by iron deficiency, hypoxia, and anemia. Transferrin-bound iron stimulates hepcidin expression in hepatocytes [24]. Inflammatory states with high interleukin (IL)-6 are followed by increased levels of hepcidin and then by hypoferremia. Hypoxia-inducible factor mediates hypoxia suppression of hepcidin.

In a cross-sectional study of a cohort of the CONTRAST study [25], 25-hepcidin levels were shown to be independently and positively associated with ferritin levels and inversely with residual renal function. Thus, hepcidin represents a common effector of the homeostatic regulation of the intracellular iron fluxes in response to iron stores, erythroid, and inflammatory regulators such as cytokines [26]. 25-Hepcidin is cleared through kidney function, and progression of renal disease has been associated with increased serum hepcidin levels [27].

We believe that, although many factors act differently in determining ESA resistance, a high blood concentration of hepcidin is probably the main final common pathway.

\section{Current Strategies to Improve ESA Hyporesponsiveness}

\section{Iron Therapy}

Although intravenous iron administration combined with high doses of ESA therapy can overcome some degree of hepcidin-mediated iron blockade, there are some reasons that suggest caution in adopting this strategy routinely. The importance of an adequate iron therapy cannot be underestimated. While iron replenishment leads to a correction of low hemoglobin levels and sparing of ESA, an unguided intravenous iron therapy may lead to iron overload with significant iron deposition and tissue injury.

Current studies have shown high liver-iron content in dialysis patients receiving intravenous iron. The longterm effects of intravenous iron and enhanced iron stores have not been rigorously investigated. Free iron rises after intravenous iron administration, which may promote infections and oxidative damage. In observational studies, the received cumulative intravenous iron dose has been linked to increased risk of death and hospitalization [9]. Similarly, high doses of ESAs should be avoided. Cardiovascular safety findings from several randomized controlled trials (RCTs) such as CHOIR [28], CREATE [29], and TREAT [30] which targeted $\mathrm{Hb}$ values $>11 \mathrm{~g} / \mathrm{dL}$, drove regulatory authorities to institute warnings to use the lowest ESA dose adequate for reducing the need for red blood cell transfusion. Similar recommendations have also been made based on observational studies.

\section{HD Techniques}

The role of HD technique on ESAs resistance treatment is controversial. HD adequacy can improve the inflammatory status and, by lowering hepcidin levels, reduce ESA requirement. In a randomized study of Costa et al. [31] on $50 \mathrm{HD}$ patients, non-responders to ESA treatment had higher C-reactive protein, lower serum albumin levels, as well as a lower number of total and CD4+ lymphocytes, in comparison with responders. This may suggest a correlation between resistance to ESA therapy and the magnitude of the inflammatory response. On the other hand, HD treatment could act removing a significant amount of hepcidin. Lowering hepcidin would release iron from stores, promote erythropoiesis, and prolong red cell survival, and therefore may be safer than high doses of ESAs with repetitive parenteral iron.

Hepcidin is a middle-molecular-weight substance with a molecular weight of 2,791 $\mathrm{Da}$ and the removal by dialysis has been demonstrated in adult patients with varying degrees of efficiency [32]. The clearance is mild in low-flux HD, intermediate by high-flux HD, and elevated in OL-HDF. Recently, we demonstrated that the use of new HD techniques and more efficient membranes that allow higher convective volume, allow the removal of larger quantities of hepcidin with a significant reduction in pre- HD levels and a consensual improvement of ESAs resistance [33]. Also Stefansson et al. [34], in a short-term study consisting of a small population of 20 patients, suggested that hepcidin levels were significantly reduced after 60 days of high volume OL-HDF with respect to lowflux HD. The role of membrane permeability in removing high quantity of hepcidin and in reducing its pre-HD levels has been confirmed by Teatini et al. [35] using a high cut-off membrane. In the study group, $50 \%$ reduction on hepcidin level was achieved and it was associated with an increase of hemoglobin level. In the control group, the pre-dialysis level of hepcidin did not change. The association of high convective volume and good membrane permeability appears to be the solution to obtain lower levels of hepcidin, better iron release from stores, and more effective erythropoiesis. 


\section{Randomized and Observational Studies}

Despite these stimulating data, randomized and observational studies designed to investigate the efficacy of OLHDF in reducing ESA resistance provided conflicting results. We reviewed studies comparing low-flux or high-flux HD versus post-dilution OL-HDF. Among observational studies, Bonforte et al. [36] studied $32 \mathrm{HD}$ patients 3 months before and 3, 6, and 9 months after the transfer to OL-HDF and showed a decrease in ESA consumption with a maximum decrease during the ninth month of follow-up. On the contrary, Oates et al. [37] in an observational study did not find a significant difference between HDF and HD but the design of the study is questionable, the 2 groups were not comparable and the results were not adjusted for any co-variables. Marcelli et al. [38], in a recently published study based on a large population of incident $\mathrm{HD}$ and $\mathrm{HDF}$ patients matched in order to limit possible bias by indication, compared the dynamics of the erythropoiesis stimulating agent resistance index between HD and HDF. Applying a sensitivity analysis stratifying by type of ESA and administration route, the authors found a clear difference between HD- and HDF-treated patients in ERI reduction limited only to those HDF patients assigned to intravenous rHuEPO treatment and showing a high baseline ERI.

Small sample size randomized studies except Ward et al. [39] showed an improvement of ERI or a reduction in ESAs consumption in post dilution OL-HDF (Lin et al. [40], Vaslaki et al. [41], Schiffl [42], Pedrini et al. [43], and Panichi et al. [33]). The study from Ward et al. [39] failed to find a significant difference between online HDF and high-flux dialysis regarding the ERI but the sample size was very small, and the groups were not well balanced, particularly for the prevalence of polycystic kidney disease (8.3\% in the HDF group vs. $23.8 \%$ in the HD group). Therefore, most observational studies and small sample size randomized trials demonstrate a positive effect of OL-HDF on ERI consumption.

\section{Randomized Controlled Trials}

The results coming from RCTs are more difficult to explain. The CONTRAST study, the Turkish OL-HDF study [44] and the ESHOL study [45]published in the period 2012-2013 are the most important trials designed to compare the effect of OL-HDF over HD on patient survival. Differences on ERI or ESAs consumption were secondary end points for all 3 studies. The CONTRAST study results concerning anemia and ESA resistance have been published more recently by Van derWeerd et al. [25] ESA was prescribed as epoetin alfa or beta or darbepoetin alfa; $73 \%$ of patients at baseline were treated by darbepoetin alfa. ESA and iron supplements were administered via the venous blood line at the end of a dialysis session. During the follow-up period, the mean levels of $\mathrm{Hb}$ were $11.9(11.8-12.0)$ in OL-HDF vs. $11.7(11.6-11.8)$ in HD and ESA index $0.41(0.38-0.45)$ in OL-HDF vs. 0.43 $(0.39-0.47)$ in HD. There was a trend toward a lower consumption of ESA in OL-HDF but the value did not reach a statistical significance. The mean dose of iron supplementation during follow-up tended to be slightly higher in the OL-HDF group as compared to HD.

The Turkish OL-HDF study enrolled 782 patients undergoing thrice-weekly HD and randomly assigned them in a 1:1 ratio to either post-dilution OL-HDF or high-flux HD. The majority of the patients receiving erythropoiesis-stimulating agents (92.2\%) used a short acting ESA, the remaining ones darbepoetin alfa. During the followup period, the ESA dose (U/week) was significantly lower in OL-HDF than in HD and ERI (U/week per kg per g/ dL) was reduced by $22 \%$ in OL-HDF vs. HD. The designs of CONTRAST study and the Turkish study were similar, as well as the convective volume in OL-HDF groups, while the mean age of enrolled patients ( 64 vs. 56.5 years) and the percentage of patients receiving ESA treatment at baseline ( 89 vs. $57 \%$ ) were different. The study populations had similar baseline levels of C-reactive protein, albumin, and hemoglobin. Ferritin and transferrin saturation levels were adequate in both but higher in Turkish study. In summary, the only strong difference in the 2 studies was the percentage of patients treated by shortacting ESAs (92 vs. $27 \%$ ).

The ESHOL study adopted a similar design but the patients on OL-HDF reached convective volume much higher than in the previous studies as a result of a higher mean blood flow rate and a longer mean length of dialysis. Differences on ESA consumption and hemoglobin levels were secondary end points. ESA-treated patients were more than $90 \%$. About half of patients were treated with short-acting ESA and the other half with a long-acting agent. No differences in hemoglobin levels, transferrin saturation index, and ferritin levels were reported between the 2 groups during the whole study period. ESA doses too were comparable between the 2 groups.

However, observing online supplementary tables of the Catalan ESHOL study [45], it is possible to differentiate patients treated with short-acting ESAs from those treated with long-acting ESAs. Considered separately, patients treated with short-acting ESAs showed an increase 
in ESAs dosage in HD and stability in OL-HDF, achieving a statistically significant difference on ESAs consumption between OL-HDF and HD.

In all these studies, a common denominator to obtain a reduction of ESA resistance on OL-HDF seems to be the use of a short-acting ESAs, as already noticed in observational studies [38].

\section{The Mechanism of ERI Reduction in OL-HDF}

OL-HDF and in particular high volume OL-HDF obtains a significant reduction of hepcidin levels. This reduction can be transient or more stable in relation to the efficacy of dialysis treatment, which correlates the magnitude of convective volume and the efficiency of the membrane in removal middle molecules. In the REDERT study, the hepcidin clearance was $103.9 \pm 20.3 \mathrm{~mL} / \mathrm{min}$ in high volume OL-HDF versus $53.3 \pm 30.3 \mathrm{~mL} / \mathrm{min}$ in $\mathrm{HD}$ $(p<0.05)$. Significantly lower pre-dialysis hepcidin levels were also observed in high volume OL-HDF treatment after 3 and 6 months with a positive linear correlation between ERI and hepcidin. These data are in contrast with the results of the study by Kuragano et al. [46] who observed a rebound immediately after the end of the session, with hepcidin returning to pre-HD levels after $3 \mathrm{~h}$. Nevertheless, patients were treated by low-flux HD, the postHD hepcidin levels were evaluated only in 10 patients in a single HD session and the reduction rate was much lower than that in our study.

In agreement with the hypothesis formulated by Marcelli et al. [38], we may speculate that if the reduction of hepcidin levels was strong and stable after dialysis treatment, the advantage associated to OL-HDF would be demonstrated with any type of ESA. Unfortunately, it is possible to achieve a significant reduction in hepcidin blood concentration for a very transient period after the end of dialysis treatment before the hepcidin rebound. Only a short-acting ESA which performs its action very rapidly is able to produce a significant improvement of erythropoiesis under these conditions. Therefore, higher hepcidin clearance combined with a short-acting ESA intravenously administered appears to be the leading mechanism of ESAs resistance lowering on OL-HDF (Fig. 1).

This hypothesis explains the apparently conflicting results of the previously mentioned studies. The improvement in ESA hyporesponsiveness is not to be searched for in a single therapeutic intervention, but rather in the combination of different measures capable of determining and exploiting a low hepcidin status. First, it is fundamen-

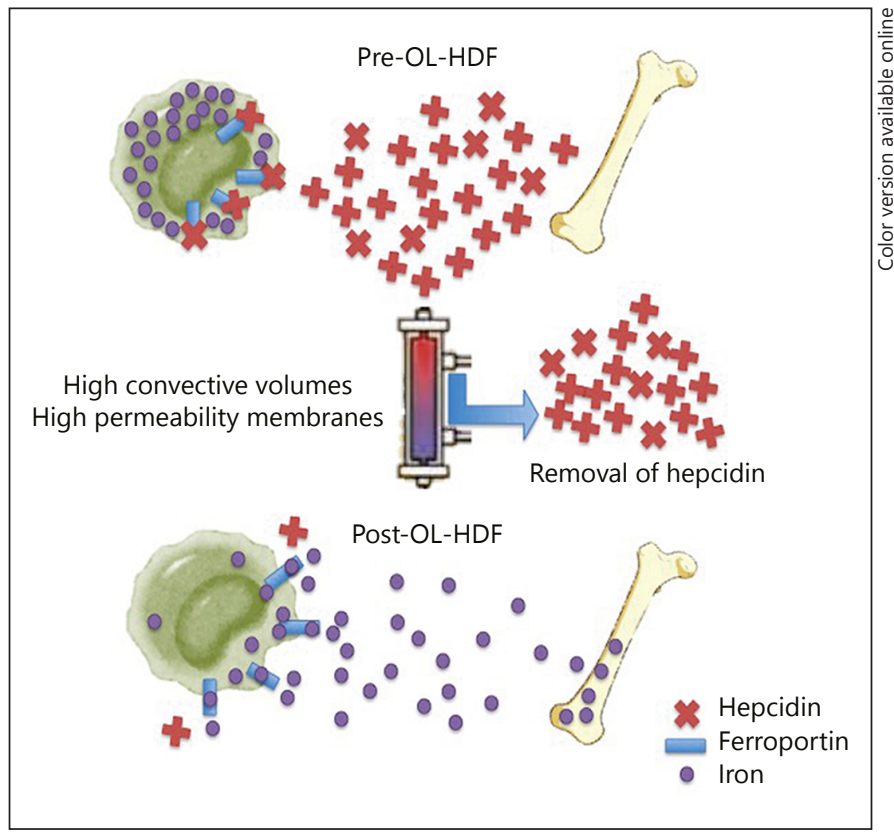

Fig. 1. Removal of hepcidin through OL-HDF contributes to iron mobilization. Pre-OL-HDF status is characterized by high levels of hepcidin, which binds to ferroportin and mediates its consequent immobilization of iron intracellular deposits. OL-HDF through high convective volumes and high permeability membranes allows greater removal of hepcidin. Immediately after the OL-HDF session, in absence of hepcidin-binding, ferroportin migrates on the membrane surface allowing iron outflow from cell to blood, available for erythropoiesis.

tal to achieve a significant reduction of hepcidin blood concentration compared to baseline levels. OL-HDF has been demonstrated to obtain a better clearance of hepcidin in patients with high baseline ERI. However, this reduction is not sufficient to improve erythropoiesis. Second, as the reduction of hepcidin blood concentration is of short duration, the erythropoietic stimulus induced by ESAs has to be concentrated in this temporal window. Erythropoiesis induced by subcutaneous ESA is slow and progressive and delayed compared to the time lapse of hepcidin reduction. For the same reason, a long-acting ESA, even if intravenously administered, is inadequate to intercept the favorable low blood hepcidin status, as it acts gradually over a span of weeks. In contrast, intravenous short-acting ESAs at the end of the OL-HDF session seem to be the only agents able to produce their effect in the low hepcidin temporal window and to show efficacy in improving ESA hyporesponsiveness. OL-HDF has therefore an important impact on anemia in ESRD patients, as it gives the basic condition to overcome ESA hyporesponsiveness, given that it is associated with the right ESA 
agent and the correct administration route. It is possible to speculate that, in this condition of lower levels of hepcidin and IV ESAs, IV iron administered at the end of the OL-HDF session could be more easily used for erythropoiesis, minimising the risk of toxin accumulation.

An additional mechanism contributing indirectly to lower hepcidin levels is the improvement of inflammatory status by OL-HDF through the reduction of IL- 6 , a powerful stimulator of hepcidin as previously mentioned. The reduction on IL- 6 of is a common finding with OLHDF techniques. Among these observations, Akoglu et al. [47] demonstrated a significant reduction of IL-6 levels on OL-HDF whereas HD with low- and high-flux polysulfone membranes did not obtain any effect on IL-6 level.

The relevance of hepcidin level reduction in improving erythropoiesis has been recently confirmed by a phase 2 , randomized study comparing a new class of drugs, hypoxia-inducible factor-prolyl hydroxylase inhibitors with epoetin alfa. This drug operates by an intermittent activation of genes associated with erythropoiesis and lowering hepcidin level. The study showed a positive impact on iron availability to overcome the therapeutic barrier to erythropoiesis from the inflammatory component present in ESRD [48].

\section{Summary}

Analyzing data from major RCTs comparing $\mathrm{HD}$ and OL-HDF (CONTRAST study, Turkish study, and ESHOL study), we can speculate that the observed differences in ESA responsiveness may result from different anemia protocols in terms of ESA type and route of administration rather than from the efficiency of OL-HDF only. Probably, if all RCTs adopted an intravenous short-acting ESA, the results would be comparable.

In HD patients, ESA hyporesponsiveness is a common finding and many factors are involved in determining this condition. The causes should be assessed and treated whenever possible. OL-HDF and in particular high volume OL-HDF coupled with a short-acting ESA is a possible strategy to improve the ESA response in most cases.

In view of the results, OL-HDF may become the firstline option in HD patients with ESA hyporesponsiveness.

\section{Disclosure Statement}

The authors have no competing interests.

\section{References}

1 Eschbach JW, Abdulhadi MH, Browne JK, Delano BG, Downing MR, Egrie JC, Evans RW, Friedman EA, Graber SE, Haley NR: Recombinant human erythropoietin in anemic patients with end-stage renal disease. Results of a phase III multicenter clinical trial. Ann Intern Med 1989;111:992.

2 Bradbury BD, Danese MD, Gleeson M, Critchlow CW: Effect of Epoetin alfa dose changes on hemoglobin and mortality in hemodialysis patients with hemoglobin levels persistently below $11 \mathrm{~g} / \mathrm{dL}$. Clin J Am Soc Nephrol 2009;4:630.

3 Zhang Y, Thamer M, Stefanik K, Kaufman J, Cotter DJ: Epoetin requirements predict mortality in hemodialysis patients. AM J Kidney Dis 2004;44:866.

4 Kausz AT, Solid C, Pereira BJ, Collins AJ, St Peter W: Intractable anemia among hemodialysis patients: a sign of suboptimal management or a marker of disease? Am J Kidney Dis 2005; $45: 136$.

5 Chapter 1: diagnosis and evaluation of anemia in CKD. Kidney Int Suppl 2012;2:288-291.

6 NKF-DOQI clinical practice guidelines for anemia of chronic renal failure. IV administration of epoetin. Am J Kidney Dis 2001; 7(suppl 1):S207.

7 Locatelli F, Aljama P, Bárány P, Canaud B, Carrera F, Eckardt KU, Hörl WH, Macdougal
IC, Macleod A, Wiecek A, Cameron S; European Best Practice Guidelines Working Group: Revised European best practice guidelines for the management of anaemia in patients with chronic renal failure. Nephrol Dial Transplant 2004;19(suppl 2):ii1-ii47.

8 Panichi V, Rosati A, Bigazzi R, Paoletti S, Mantuano E, Beati S, Marchetti V, Bernabini G, Grazi G, Rizza GM, Migliori M, Giusti R, Lippi A, Casani A, Barsotti G, Tetta C; RISCAVID Study Group: Anaemia and resistance to erythropoiesis-stimulating agents as prognostic factors in haemodialysis patients: results from the RISCAVID study. Nephrol Dial Transplant 2011; 26:2641-2648.

9 Rosati A, Tetta C, Merello JI, Palomares I, Perez-Garcia R, Maduell F, Canaud B, Aljama Garcia P: Cumulative iron dose and resistance to erythropoietin. J Nephrol 2015;28:603-613.

10 Elliott J, Mishler D, Agarwal R: Hyporesponsiveness to erythropoietin: causes and management. Adv Chronic Kidney Dis 2009;16: 94-100.

11 Kalantar-Zadeh K, Ikizler TA, Block G, Avram MM, Kopple JD: Malnutrition-inflammation complex syndrome in dialysis patients: causes and consequences. Am J Kidney Dis 2003;42:864-881.

12 Rao DS, Shih MS, Mohini R: Effect of serum parathyroid hormone and bone marrow fi- brosis on the response to erythropoietin in uremia. N Engl J Med 1993;328:171.

13 Schiffl H, Lang SM: Folic acid deficiency modifies the hematopoietic response to recombinant human erythropoietin in maintenance dialysis patients. Nephrol Dial Transplant 2006;21:133

14 Mallick S, Rafiroiu A, Kanthety R, Iqbal S, Malik R, Rahman M: Factors predicting erythropoietin resistance among maintenance hemodialysis patients. Blood Purif 2012;33:238244.

15 Ifudu O, Feldman J, Friedman EA: The intensity of hemodialysis and the response to erythropoietin in patients with end-stage renal disease. N Engl J Med 1996;334:420425 .

16 Movilli E, Cancarini GC, Zani R, Camerini C, Sandrini M, Maiorca R: Adequacy of dialysis reduces the doses of recombinant erythropoietin independently from the use of biocompatible membranes in haemodialysis patients. Nephrol Dial Transplant 2001;16:111114.

17 Hsu PY, Lin CL, Yu CC, Chien CC, Hsiau TG, Sun TH, Huang LM, Yang CW: Ultrapure dialysate improves iron utilization and erythropoietin response in chronic hemodialysis patients - a prospective cross-over study. J Nephrol 2004;17:693-700.
Hepcidin and HDF Online in the Response to Erythropoiesis Stimulating Agents 
18 Locatelli F, Altieri P, Andrulli S, Sau G, Bolasco P, Pedrini LA, Basile C, David S, Feriani M, Nebiolo PE, Ferrara R, Casu D, Logias F, Tarchini R, Cadinu F, Passaghe M, Fundoni G, Villa G, Di Iorio BR, Zoccali C: Predictors of hemoglobin levels and resistance to erythropoiesis-stimulating agents in patients treated with low-flux haemodialysis, haemofiltration and haemodiafiltration: results of a multicentre randomized and controlled trial. Nephrol Dial Transplant 2012;27:3594-3600.

19 Krause A, Neitz S, Mägert HJ Schulz A, Forssmann WG, Schulz-Knappe P, Adermann K: LEAP-1, a novel highly disulfide-bonded human peptide, exhibits antimicrobial activity. FEBS Lett 2000;480:147-150.

20 Park $\mathrm{CH}$, Valore EV, Waring AJ, Ganz T: Hepcidin, a urinary antimicrobial peptide synthesized in the liver. J Biol Chem 2001;276: 7806-7810

21 Babitt JL, Lin HY: Molecular mechanisms of hepcidin regulation: implications for the anemia ofCKD. Am J Kidney Dis 2010;55:726-741.

22 Pigeon C, Ilyin G, Courselaud B, Leroyer P, Turlin B, Brissot P, Loréal O: A new mouse liver-specific gene, encoding a protein homologous to human antimicrobial peptide hepcidin, is overexpressed during iron overload. J Biol Chem 2001;276:7811-7819.

23 Nemeth E, Tuttle MS, Powelson J, Vaughn MB, Donovan A, Ward DM, Ganz T, Kaplan $\mathrm{J}$ : Hepcidin regulates cellular iron efflux by binding to ferroportin and inducing its internalization. Science 2004;306:2090-2093.

24 Lin L, Valore EV, Nemeth E, Goodnough JB, Gabayan V, Ganz T: Iron transferrin regulates hepcidin synthesis in primary hepatocyte culture through hemojuvelin and BMP2/4. Blood 2007;110:2182-2189.

25 Van derWeerd NC, Grooteman MP, Bots ML, van den Dorpel MA, den Hoedt CH, Mazairac AH, Nubé MJ, Penne EL, Gaillard CA, Wetzels JF, Wiegerinck ET, Swinkels DW, Blankestijn PJ, Ter Wee PM; CONTRAST Investigators: Hepcidin-25 in chronic hemodialysis patients is related to residual kidney function and not to treatment with erythropoiesis stimulating agents. PLoS One 2012;7:e39783.

26 Nemeth E, Rivera S, Gabayan V Keller C, Taudorf S, Pedersen BK, Ganz T: IL-6 mediates hypoferremia of inflammation by inducing the synthesis of the iron regulatory hormone hepcidin. J Clin Invest 2004;113:12711276.

27 Ashby DR, Gale DP, Busbridge M, Murphy KG, Duncan ND, Cairns TD, Taube DH, Bloom SR, Tam FW, Chapman RS, Maxwell $\mathrm{PH}$, Choi P: Plasma hepcidin levels are elevated but responsive to erythropoietin therapy in renal disease. Kidney Int 2009;75:976-981.

28 Inrig JK, Sapp S, Barnhart H, Patel UD, Reddan D, Singh A, Califf RM, Szczech L: Impact of higher hemoglobin targets on blood pressure and clinical outcomes: a secondary analysis of CHOIR. Nephrol Dial Transplant. 2012;27:3606-3614.
29 Locatelli F, Del Vecchio L, Pozzoni P: Anemia and cardiovascular risk: the lesson of the CREATE trial. J Am Soc Nephrol 2006;17(12 suppl 3):S262-S266.

30 Locatelli F, Aljama P, Canaud B, Covic A, De Francisco A, Macdougall IC, Wiecek A, Vanholder R; Anaemia Working Group of European Renal Best Practice (ERBP): Target haemoglobin to aim for with erythropoiesisstimulating agents: a position statement by ERBP following publication of the Trial to reduce cardiovascular events with Aranesp therapy (TREAT) study. Nephrol Dial Transplant 2010;25:2846-2850.

31 Costa E, Lima M, Alves JM, Rocha S, RochaPereira P, Castro E, Miranda V, do SF, Loureiro A, Quintanilha A, Belo L, Santos-Silva A: Inflammation, T-cell phenotype, and inflammatory cytokines in chronickidney disease patients under hemodialysis and its relationship to resistance to recombinant human erythropoietin therapy. J Clin Immunol 2008;28:268-275.

32 Zaritsky J, Young B, Gales B, Wang HJ, Rastogi A, Westerman M, Nemeth E, Ganz T, Salusky IB: Reduction of serum hepcidin by hemodialysis in pediatric and adult patients. Clin J Am Soc Nephrol 2010;5:1010-1014.

33 Panichi V, Scatena A, Rosati A, Giusti R, Ferro G, Malagnino E, Capitanini A, Piluso A, Conti P, Bernabini G, Migliori M, Caiani D, Tetta C, Casani A, Betti G, Pizzarelli F: Highvolume online haemodiafiltration improves erythropoiesis-stimulating agent (ESA) resistance in comparison with low-flux bicarbonate dialysis: results of the REDERT study. Nephrol Dial Transplant 2015;30:682-689.

34 Stefánsson BV, Abramson M, Nilsson U, Haraldsson B: Hemodiafiltration improve plasma 25-hepcidin levels: a prospective, randomized, blinded, cross-over study comparing hemodialysis and hemodiafiltration. Nephron Extra 2012;2:55-65.

35 Teatini U, Liebchen A, Nilsson LG, Beck W, Romei Longhena G: Effect of a more permeable dialysis membrane on ESA resistance in hemodialysis patients - a pilot investigation. Blood Purif 2016;41:80-86.

36 Bonforte G, Grillo P, Zerbi S, Surian M: Improvement of anemia in hemodialysis patients treated by hemodiafiltration with highvolume on-line prepared substitution fluid. Blood Purif 2002;20:357-363.

37 Oates T, Pinney JH, Davenport A: Haemodiafiltration versus high-flux haemodialysis: effects on phosphate control and erythropoietin response. Am J Nephrol. 2011;33:70-75.

38 Marcelli D, Bayh I, Merello JI, Ponce P, Heaton A, Kircelli F, Chazot C, Di Benedetto A, Marelli C, Ladanyi E, Kroczak M, Stuard S, Grassmann A, Scatizzi L, Brand K, Canaud B: Dynamics of the erythropoiesis stimulating agent resistance index in incident hemodiafiltration and high-flux hemodialysis patients. Kidney Int 2016;90:192-202.

39 Ward RA, Schmidt B, Hullin J, Hillebrand GF, Samtleben W: A comparison of on-line hemodiafiltration and high-flux hemodialysis: a prospective clinical study. J Am Soc Nephrol 2000;11:2344-2350.

40 Lin CL, Huang CC, Yu CC, Wu CH, Chang CT, Hsu HH, Hsu PY, Yang CW: Improved iron utilization and reduced erythropoietin resistance by on-line hemodiafiltration. Blood Purif 2002;20:349-356.

41 Vaslaki L, Major L, Berta K, Karatson A, Misz M, Pethoe F, Ladanyi E, Fodor B, Stein G, Pischetsrieder M, Zima T, Wojke R, Gauly A, Passlick-Deetjen J: On-line haemodiafiltration versus haemodialysis: stable haematocritwith less erythropoietin and improvement of other relevant blood parameters. Blood $\mathrm{Pu}$ rif 2006;24:163-173.

42 Schiffl H: Prospective randomized cross-over long-term comparison of online haemodiafiltration and ultrapure high-flux haemodialysis. Eur J Med Res 2007;12:26-33.

43 Pedrini LA, De Cristofaro V, Comelli M, Casino FG, Prencipe M, Baroni A, Campolo G, Manzoni C, Coli L, Ruggiero P, Acquistapace I, Auriemma L: Long-term effects of high-efficiency on-line haemodiafiltration on uraemic toxicity. A multicentre prospective randomized study. Nephrol Dial Transplant 2011;26:2617-2624.

44 Ok E, Asci G, Toz H, Ok ES, Kircelli F, Yilmaz M, Hur E, Demirci MS, Demirci C, Duman S, Basci A, Adam SM, Isik IO, Zengin M, Suleymanlar G, Yilmaz ME, Ozkahya M; Turkish Online Haemodiafiltration Study: Mortality and cardiovascular events in online haemodiafiltration (OL-HDF) compared with highflux dialysis: results from the Turkish OLHDF Study. Nephrol Dial Transplant 2013; 28:192-202.

45 Maduell F, Moreso F, Pons M, Ramos R, Mora-Macià J, Carreras J, Soler J, Torres F, Campistol JM, Martinez-Castelao A; ESHOL Study Group: High-efficiency postdilution online hemodiafiltration reduces all-cause mortality in hemodialysis patients. J Am Soc Nephrol 2013;24:487-497.

46 Kuragano T, Shimonaka Y, Kida A, Furuta M, Nanami M, Otaki Y, Hasuike Y, Nonoguchi $\mathrm{H}$, Nakanishi T: Determinants of hepcidin in patients on maintenance hemodialysis: role of inflammation. Am J Nephrol 2010;31:534540.

47 Akoglu H, Dede F, Piskinpasa S, Falay MY, Odabas AR: Impact of low- or high-flux haemodialysis and online haemodiafiltration on inflammatory markers and lipid profile in chronic haemodialysis patients. Blood Purif 2013;35:258-264.

48 Provenzano R, Besarab A, Wright S, Dua S, Zeig S, Nguyen P, Poole L, Saikali KG, Saha G, Hemmerich S, Szczech L, Yu KH, Neff TB: Roxadustat (FG-4592) versus epoetin alfa for anemia in patients receiving maintenance hemodialysis: a phase 2, randomized, 6- to 19 week, open-label, active-comparator, doseranging, safety and exploratory efficacy study. Am J Kidney Dis 2016;67:912-924. 